\title{
Modeling Lipase-Catalyzed Biodiesel Production in $\left[\mathrm{BMIM}^{\mathrm{B}}\left[\mathbf{P F}_{6}\right]\right.$
}

\author{
JianJun Yang ${ }^{1,2}$ and MingYan Yang ${ }^{1}$ \\ ${ }^{1}$ Department of Chemical Engineering, School of Environment Science and Engineering, Chang'an University, Xian 710054, China \\ ${ }^{2}$ Opening Research Laboratory about Water Resource and Land Environment in Arid and Semiarid Region, Ministry of Land Resource, \\ Chang'an University, Xian 710054, China
}

Correspondence should be addressed to JianJun Yang; mysyjj@163.com

Received 17 October 2015; Revised 20 December 2015; Accepted 24 December 2015

Academic Editor: Francisco Javier Deive

Copyright (C) 2016 J. Yang and M. Yang. This is an open access article distributed under the Creative Commons Attribution License, which permits unrestricted use, distribution, and reproduction in any medium, provided the original work is properly cited.

\begin{abstract}
Lipase-catalyzed biodiesel production models in room temperature ionic liquids (RTILs) reaction medium available in the literature are valid especially for mixing intensity. In this paper, a preliminary model is established in order to try to describe the lipasecatalyzed biodiesel production process in RTILs in a stirring type bioreactor. Mixing intensity and time delay were inspected for the reaction model in $[\mathrm{BMIM}]\left[\mathrm{PF}_{6}\right]$ medium. As a result, this model is a good explanation for these actual reaction conditions in RTILs. The model prediction curves well describe the experimental data indicating this bioenzymatic reaction model is effective and reliable in certain conditions.
\end{abstract}

\section{Introduction}

In recent years, more and more researchers have paid their attention to enzymatic catalysis in ionic liquids as a new type of nonaqueous medium [1]. Their present reports [2,3] focused on screening of ionic liquids and process parameters (such as temperature and substrate concentration). Ionic liquid medium system which could not provide the basis for its industrial design is different from organic solvent-based medium systems and the traditional strong or weak electrolyte system. It is the most important issue for researchers to effectively remove impurities in ionic liquid medium system. Firstly, the decline of lipase activity may be related to accumulation of impurities that affect the recovery and recycling of ionic liquids in ionic liquid medium system. Secondly, there is the absence of ion mass transfer law and theoretical basis related to guide industrial producing in ionic liquid medium systems and optimizing the design of reactors related.

Due to coexisting electrostatic and hydrogen, determination, analysis, and characterization of ionic liquid medium system are not available with the traditional laws of fluid flow and mass transfer [4]. There are no apparatus and instruments to meet understanding of the mass transfer law in ionic liquid reaction systems. For immobilized enzymes, ionic liquid reaction systems are multiphase systems. The kinetic equation which includes the reaction rate and the transfer rate is the theoretical basis for designing the immobilized enzyme catalytic reactor and its operating conditions. In this paper, mass transfer law about immobilized lipase was studied in RTILs medium system for its industrial application.

\section{Materials and Methods}

2.1. Materials. Lipase from Candida antarctica $\left(5000 \mathrm{U} \cdot \mathrm{g}^{-1}\right)$, BSA, and nonporous silica gel were purchased from Merck A.G. (Darmstadt, Germany); n-tridecane was purchased from Geel (Belgium); methyl palmitate, methyl stearate, methyl oleate, ethyl oleate, methyl linoleate, and methyl linolenate were purchased from AccuStandard (USA); polyethylene glycol 6000, 1-butyl-3-methylimidazolium hexafluorophosphate ([BMIM] $\left.\left[\mathrm{PF}_{6}\right]\right)$, and 1-butyl-3-methylimidazolium tetrafluoroborate ([BMIM] $\left.\left[\mathrm{BF}_{4}\right]\right)$ were obtained from China Chemical Group Co., Xi'an, China. All other chemicals used were of analytical grade. 


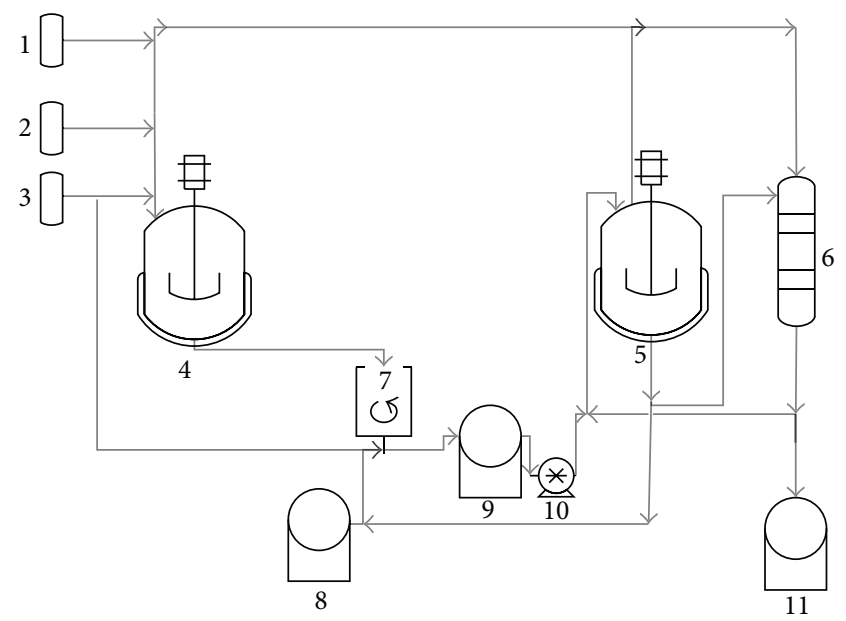

(1) Low carbon alcohol tank

(7) Separator

(2) Ionic liquid tank

(8) Glycerin tank

(3) Animal fats tank

(9) Fatty acid tank

(4) Lipase reactor A

(10) Pump

(5) Lipase reactor B

(11) Biodiesel tank

(6) Distillation column

Figure 1: Process of producing biodiesel catalyzed by Limczyme in $[\mathrm{BMIM}]\left[\mathrm{PF}_{6}\right]$.

\subsection{Methods}

2.2.1. Lipase Immobilization by Modification and Conjugation with Silica Gel Carrier. $1 \mathrm{~g}$ of carrier (activated silica gelPEG) was mixed with $10 \mathrm{~mL}$ of lipase solution consisting of lipase dissolved in $\mathrm{pH} 7.5,0.05 \mathrm{M}$ phosphate buffer for $24 \mathrm{~h}$ at low temperature. After reaction, the sediment was washed with phosphate buffer three times and kept at $4^{\circ} \mathrm{C}$. The lipase immobilized by modification and conjugation method with silica gel carriers is referred to as Limczyme [5].

2.2.2. GC Analysis. Sample $(300 \mu \mathrm{L})$ taken from the reaction mixture was mixed with $100 \mu \mathrm{L}$ of water and $100 \mu \mathrm{L}$ of hexane to extract fatty acid methyl esters (FAMEs). Hexane of $90 \mu \mathrm{L}$ phase which contains FAMEs was mixed with $10 \mu \mathrm{L}$ of n-tridecane (internal standard). The methyl ester contents in the reaction mixture were quantified by a SP-3420 gas chromatograph (Beijing Beifen-Ruili Analytical Instrument Co., Ltd., China) using a KB-1 capillary column $(30 \mathrm{~m} \times$ $0.25 \mathrm{~mm} \times 0.25 \mu \mathrm{m}, \mathrm{Kromat}$, USA). The oven temperature was kept at $120^{\circ} \mathrm{C}$ for $1 \mathrm{~min}$, raised to $280^{\circ} \mathrm{C}$ at $10^{\circ} \mathrm{C}$ per minute, and maintained at this temperature for $1 \mathrm{~min}$. The temperatures of the injector and detector were set at $290^{\circ} \mathrm{C}$ and $300^{\circ} \mathrm{C}$, respectively. Pure nitrogen was used as a carrier gas. The volume of injected sample was $2 \mu \mathrm{L}$.

2.2.3. Production Process. Experimental process was shown in Figure 1 for producing biodiesel. Relying on liquid level different, raw materials as short-chain alcohols, ionic liquids, and oils, respectively, get into enzymatic reaction tanks 4 and 5 from storage tanks 1, 2, and 3. As bioreactors, there are not any differences between tank 4 and tank 5. Respectively, tank 4 and tank 5 are responsible for two steps of producing biodiesel. It is the only difference that oils material for tank 5 is not from raw oils (from tank 3) but mainly from unreacted oils which are separated from products of tank 4 with separator 7 .

As is shown in Figure 1, methanol is continuously added to reactor 4 and reactor 5 to complete this reaction with a certain methanol flow and the total molar ratio of methanol to triglyceride is $3: 1$ for the process of producing biodiesel. That is to say, methanol is not added to reactor in one step but step by step.

Tank 8 is used for storing by-product glycerol, tank 9 for storing unreacted oils and newly generated free fatty acids, and tank 11 for storing product biodiesel from distillation column 6. Mass transfer processes of lipase-catalyzed production of biodiesel were studied in stirred enzyme reactor in the closed continuous process. The optimization that can give three sets of process parameters to the production was gained by the systemic research on three groups of reaction systems which were shown in Table 1.

2.2.4. Establishment of Reaction Model. We could simulate the transesterification process in different media reaction systems, mainly which are $[\mathrm{BMIM}]\left[\mathrm{PF}_{6}\right]$ and $[\mathrm{BMIM}]\left[\mathrm{BF}_{4}\right]$. In view of previous finding that $[\mathrm{BMIM}]\left[\mathrm{PF}_{6}\right]$ offers a superior solvent for lipase-catalyzed biodiesel production from oil as compared to the commonly used organic solvent [5-7], Limczyme as immobilized lipase modified by PEG 6000 that is a hydrophilic material should be surrounded by a layer of necessary water and methanol in $[\mathrm{BMIM}]\left[\mathrm{PF}_{6}\right]$ that is a hydrophobic material. So sphere micelle (water in oil) could be found in $[\mathrm{BMIM}]\left[\mathrm{PF}_{6}\right]$ reaction system when the water content was $8-10 \%$. With stirring, there are water, methanol, Limczyme, and glycerol in the hydrophilic phase and $[\mathrm{BMIM}]\left[\mathrm{PF}_{6}\right]$ and triglycerides in the hydrophobic phase.

The molecular spatial structure diagram of Limczyme shows in Figure 5.

In order to simulate mass transfer model simplified, we could ignore the impact of internal resistance of Limczyme itself on mass transfer process of transesterification. On the other hand, the external resistance to mass transfer process should be mainly considered for the contact between substrate reactive groups and lipase activity center. To overcome the external mass transfer resistance mainly depends on stirring frequency of stirrer in enzyme reactor.

Two multiplication factors related with stirring frequency of stirrer should be included in this model [8]. One factor $\eta$ is the effectiveness factor affecting the reaction rate in different stirring frequency conditions. Another factor $\theta$ is the time delay factor related with system dynamic response. Therefore, (1) could be modified as follows:

$$
\frac{d C}{d t}=f(C, T) \cdot H(t-\theta) \cdot \eta
$$

where $C$ is the concentration of chemical species, $\mathrm{mol} \cdot \mathrm{L}^{-3}$; $t$ is reaction time, $\min ; T$ is reaction temperature, $K$; $f$ is known nonlinear function; $H$ is Heaviside function; and 
TABLE 1: Process parameters of different reaction systems of producing FAMEs catalyzed by Limczyme.

\begin{tabular}{|c|c|c|c|c|c|c|c|}
\hline \multirow[b]{2}{*}{ Reaction systems } & \multicolumn{5}{|c|}{ Parameters } & \multirow[b]{2}{*}{ Reaction media } & \multirow[b]{2}{*}{ Catalyst } \\
\hline & $\mathrm{pH}$ & $T(\mathrm{~K})$ & Alcohol to oil & $\begin{array}{l}\text { Stirring rate } \\
(\mathrm{rpm})\end{array}$ & $\begin{array}{c}\text { Water } \\
\text { content }(\%)\end{array}$ & & \\
\hline 1 & \multirow{3}{*}{7.5} & 308 & $2: 1$ & 400 & 8 & {$[\mathrm{BMIM}]\left[\mathrm{PF}_{6}\right]$} & \multirow{3}{*}{ Limczyme } \\
\hline 2 & & 313 & $1: 1$ & 300 & 10 & {$[\mathrm{BMIM}]\left[\mathrm{BF}_{4}\right]$} & \\
\hline 3 & & 313 & $1: 1$ & 300 & 10 & {$[\mathrm{BMIM}]\left[\mathrm{PF}_{6}\right]$} & \\
\hline
\end{tabular}

$\theta$ is time delay factor, min. A time delay depends on stirring frequency of the stirrer. $\eta$ is the effectiveness factor. An effectiveness factor accounts for the change of the net reaction rate according to stirring frequency.

Effectiveness factor generally is used to simulate the reaction system in which solid particles (catalyst particles) are involved and also a porous solid reactant system. Effectiveness factor is defined as the ratio of the apparent reaction rate to the reaction rate. It should be homogeneous to reactants on the particles surface in reaction medium. Furthermore, all solid material particulates should get in touch with reactants [9].

Via experimental data processing and analyzing, the efficiency factor $\theta$ which is selected to be a Boltzmann sigmoid could be written as

$$
\begin{aligned}
& \eta=\frac{k_{1}}{1+\exp \left(-k_{2} \cdot\left(r-k_{3}\right)\right)}, \\
& \theta=\exp \left(\frac{k_{4}}{r}\right)+k_{5},
\end{aligned}
$$

where $r$ is stirring rate, rpm. Experimental data for different stirring frequency were used to estimate the set of the model parameters: $k_{1}, k_{2}, k_{3}, k_{4}$, and $k_{5}$. After some mathematical operations, (1) could be given:

$$
\begin{gathered}
\frac{d C}{d t}=f(C, T) \cdot H\left(t-\exp \left(\frac{k_{4}}{r}\right)-k_{5}\right) \\
\cdot \frac{k_{1}}{1+\exp \cdot\left(-k_{2}\left(r-k_{3}\right)\right)} .
\end{gathered}
$$

In addition, a molecule of triglyceride (TG) may be converted into three molecules of methyl ester, a molecule of diglyceride (DG) into two molecules, and a molecule of monoglyceride (MG) into only one molecule. The molar conversion into methyl ester is defined as the molar ratio between the methyl ester actually produced and the initial maximum amount of ester in $[\mathrm{BMIM}]\left[\mathrm{PF}_{6}\right]$ reaction system. The maximum conversion $(R=1)$ is obtained when TG, DG, and MG are completely converted into methyl ester. As a result, methanol is in excess. The conversion into methyl esters is computed from the state variables of the model:

$$
R=\frac{3\left(C_{\mathrm{TG}, 0}-C_{\mathrm{TG}}\right) M_{\mathrm{TG}}+2\left(C_{\mathrm{DG}, 0}-C_{\mathrm{DG}}\right) M_{\mathrm{DG}}+\left(C_{\mathrm{MG}, 0}-C_{\mathrm{MG}}\right) M_{\mathrm{MG}}}{3 C_{\mathrm{TG}, 0} M_{\mathrm{TG}}+2 C_{\mathrm{DG}, 0} M_{\mathrm{DG}}+C_{\mathrm{MG}, 0} M_{\mathrm{MG}}},
$$

where $C_{i}$ and $C_{i, 0}$ represent the molar concentration and molar mass of the chemical species $i$ at a reaction time and at initial time $(t=0)$, respectively. $M_{i}$ represents molar mass of chemical species $i$.

\section{Results and Discussion}

3.1. Determination of Reaction Model. Previous study [10] showed that the kinetics of Limczyme-catalyzed production of biodiesel was consistent with the double substrates pingpong Bi-Bi mechanism of alcohol inhibition mechanism. In $[\mathrm{BMIM}]\left[\mathrm{PF}_{6}\right]$ reaction medium Limczyme kinetics rate equation is as follows:

$v$

$$
=\frac{V_{\max }\left[S_{1}\right]\left[S_{2}\right]}{a K_{m 1} \times\left[S_{2}\right]+K_{m 2} \times\left[S_{1}\right]+\left(1+K_{m 2} / K_{\mathrm{iMe}}\right) \times\left[S_{1}\right]\left[S_{2}\right]} .
$$

$V_{\max }$ is the largest reaction rate $\left(\mathrm{mol} \cdot \mathrm{m}^{-3} \cdot \mathrm{min}^{-1} \cdot \mathrm{g}^{-1}\right)$, $a K_{m 1}$ is the Michaelis constant of Tung oil $\left(\mathrm{mol} \cdot \mathrm{m}^{-3}\right), K_{m 2}$ is the Michaelis constant of methanol $\left(\mathrm{mol} \cdot \mathrm{m}^{-3}\right)$, and $K_{\mathrm{iMe}}$ is the methanol inhibition constant $\left(\mathrm{mol} \cdot \mathrm{m}^{-3}\right)$. The correlation coefficients in formula (6) are as shown in Table 2 [10].

Obviously, fluctuating reaction temperatures have a certain effect on the reaction rate with the correlation coefficients. In a certain temperature range, the effect of temperature on reaction rate could be neglected [5]. But by solving correlation coefficients, the relationship between variables should be accurately expressed with model (6):

$$
\begin{aligned}
& \frac{d C}{d t} \\
& =\frac{V_{\mathrm{max}} \cdot C_{\mathrm{oil}} \cdot C_{\mathrm{Me}}}{a K_{m 1} \cdot C_{\mathrm{Me}}+K_{m 2} \cdot C_{\mathrm{oil}}+\left(1+K_{m 2} / K_{\mathrm{iMe}}\right) \cdot C_{\mathrm{oil}} \cdot C_{\mathrm{Me}}} \\
& \quad \cdot H\left(t-\exp \left(\frac{k_{4}}{r}\right)-k_{5}\right) \cdot \frac{k_{1}}{1+\exp \left(-k_{2} \cdot\left(r-k_{3}\right)\right)},
\end{aligned}
$$

where $f(C, T)=v, C_{\text {oil }}=\left[S_{1}\right]$, and $C_{\mathrm{Me}}=\left[S_{2}\right]$. 
TABLE 2: Kinetic coefficients of Limczyme.

\begin{tabular}{lccc}
\hline$V_{\max }\left(\mathrm{mol} \cdot \mathrm{m}^{-3} \cdot \mathrm{min}^{-1} \cdot \mathrm{g}^{-1}\right)$ & $a K_{m 1}\left(\mathrm{~mol} \cdot \mathrm{m}^{-3}\right)$ & $K_{m 2}\left(\mathrm{~mol} \cdot \mathrm{m}^{-3}\right)$ & $K_{\mathrm{iMe}}\left(\mathrm{mol} \cdot \mathrm{m}^{-3}\right)$ \\
\hline $1.72 \times 10^{-3}$ & 0.6192 & 1.3485 & 0.2413 \\
\hline
\end{tabular}

TABLE 3: Coefficients of the developed models and corresponding values of the objective function.

\begin{tabular}{|c|c|c|c|c|c|c|c|}
\hline \multirow{2}{*}{ Reaction system } & \multicolumn{5}{|c|}{ Parameters } & \multirow{2}{*}{$J$} & \multirow{2}{*}{$R^{2}$} \\
\hline & $k_{1}$ & $k_{2} / \mathrm{rpm}^{-1}$ & $k_{3} / \mathrm{rpm}$ & $k_{4} / \mathrm{rpm}$ & $k_{5} / \mathrm{min}$ & & \\
\hline 1 & 2.3679 & 0.0010 & 260.4237 & 482.2605 & -2.1938 & 659 & 0.980 \\
\hline 2 & 1.3281 & 0.3082 & 83.6192 & 268.8961 & -0.8663 & 2958 & 0.962 \\
\hline 3 & 1.0128 & 0.0696 & 194.6682 & 128.1065 & -1.1821 & 213 & 0.996 \\
\hline
\end{tabular}

Based on model (7), the model coefficients that cannot be measured precisely could be estimated by MATLAB software analysis for different reaction systems as in Table 3.

Adamczak et al. [11] reported that it is necessary that a certain amount of water molecules should be around lipase molecules to maintain its catalytic activity in ionic liquid reaction system. When the hydrophilic $[\mathrm{BMIM}]\left[\mathrm{BF}_{4}\right]$ could take water molecules off lipase molecules, that will result in lower lipase catalytic activity, but hydrophobic [BMIM] $\left[\mathrm{PF}_{6}\right]$ could reject water molecules as necessary water for enzymatic activity to lipase molecules [12]. Therefore, it is more difficult for Limczyme with enough necessary water to keep its catalytic activity in reaction system 2 than in reaction systems 1 and 3 .

In addition, the stable structure of $[\mathrm{BMIM}]\left[\mathrm{PF}_{6}\right]$ and its strong polar molecules had maintained the spatial "rigid" molecule structure of lipase, so that the active sites of lipase molecules were not damaged and are able to achieve the desired results. System 3 whose correlation coefficient is 0.996 would be the best choice in this paper. The established reaction models should be investigated in the following sections only according to experimental data and predicted values in reaction system 3 .

3.2. Effect of Mixing Intensity on the Oil Conversion Rate. Under the stirring rate of $100 \mathrm{rpm}, 300 \mathrm{rpm}$, and $500 \mathrm{rpm}$, the effect of mixing intensity on reaction model was examined (Figure 2). Further adjust and modify the model so that stirring rate change does not affect the predictive capability of reaction model.

As shown in Figure 3, the reaction model established accurately predicts the obviously nonlinear relationship between stirring rate and time delay in the whole reaction process. Low stirring intensity which leads to system response delay is not conducive to transesterification process. The lower the stirring intensity is, the more significant the system response delay is. We improve modeling strategies to reflect the impact of stirring rate on transesterification during the experiment [13].

Mixing intensity is much smaller in practical situations than in ideal situations due to limiting mass transfer of interaction between reactants. For biodiesel production process the reaction mixture is heterogeneous because oil and alcohol have immiscibility. Short-chain alcohols stirred could

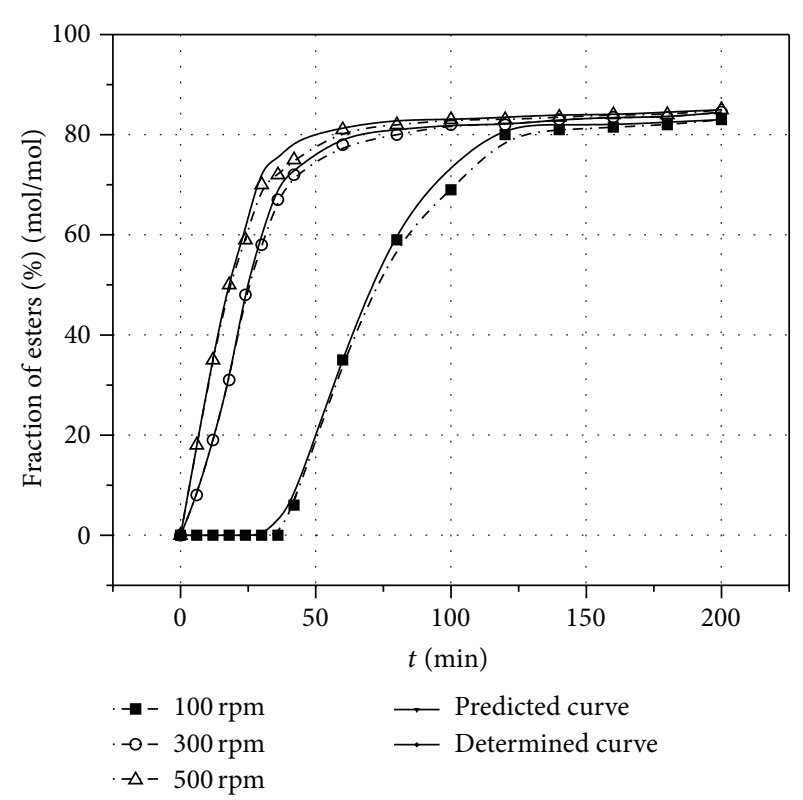

FIGURE 2: Effect of mixing intensity on the oil conversion into methyl ester.

homogeneously disperse in the oil to increase the interface area, to improve contact and mass transfer between reactants.

This reaction model is established under stirring rate $200 \mathrm{rpm}$. Predicted relevant data is smaller under $90 \mathrm{rpm}$ than $200 \mathrm{rpm}$. The predicted results as in Figure 4 show that there is no mass transfer phenomenon and transesterification has not occurred under $60 \mathrm{rpm}$. Therefore, the reaction model is relevant to the stirring rate under which the model was established. This model is not usually used to predict that lipase-catalyzed transesterification in other reaction systems under other stirring rates.

3.3. Effect of Time Delay on the Oil Conversion. The response time delay of the model is shown with solid line corresponding to the prediction model in Figure 5. Model prediction curve changed indicates that the mass transfer control begins to occur when reaction time is 15 minutes. This may be because a certain time delay was not taken into account for the actual reaction itself while model parameters were determined. Data acquisition of response time is carried 


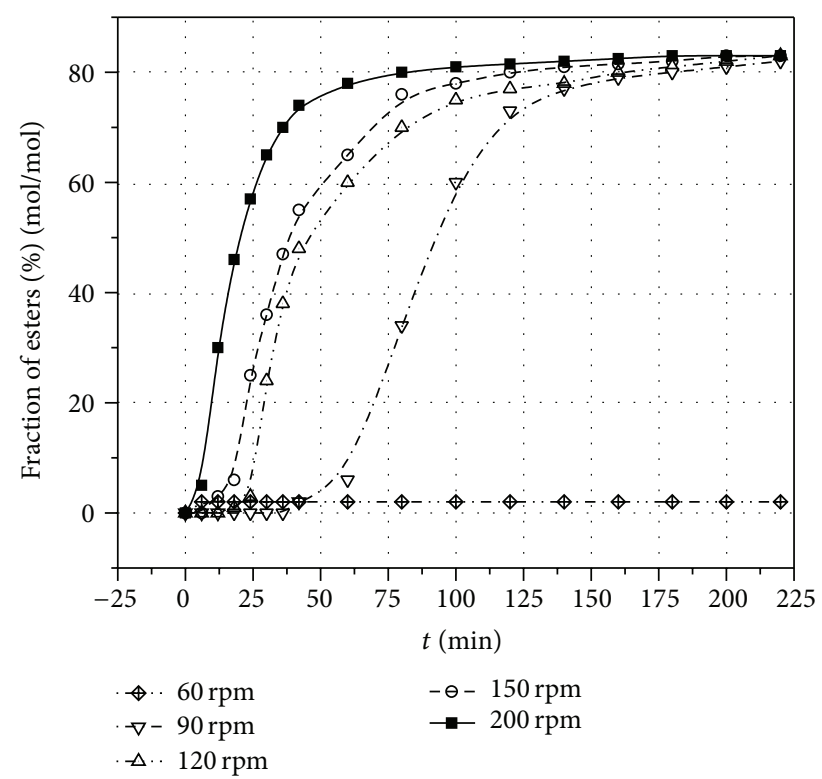

FIGURE 3: Effect of mixing intensity on the oil conversion into methyl ester.

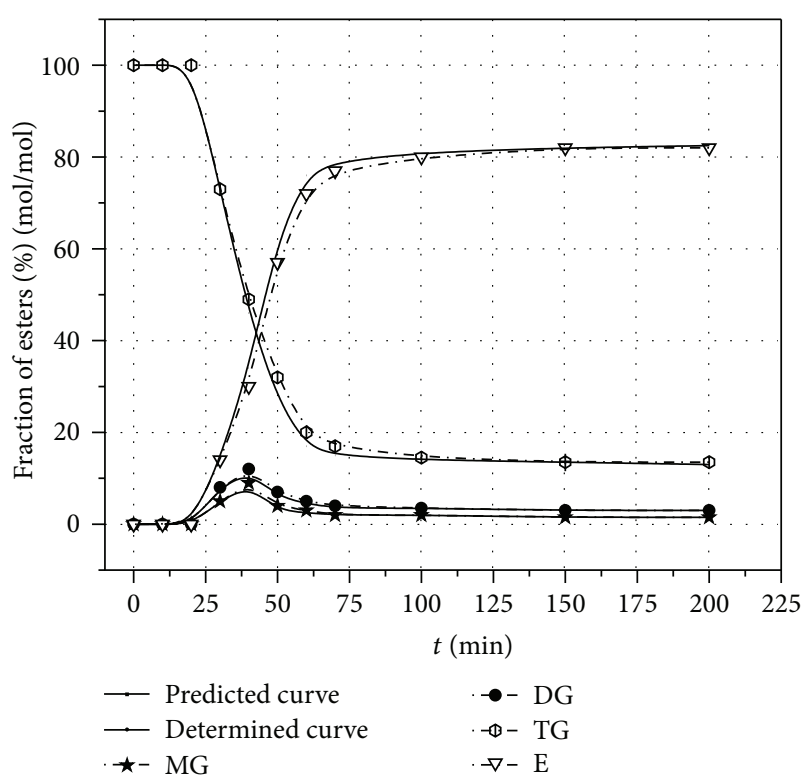

FIGURE 4: Effect of stirring rate on ester production.

out from the product generation, while ignoring the initial response time of no FAMEs product which is not expressed in the reaction kinetic model established. However, transesterification has occurred during this period of response time ignored when triglyceride (TG) reacts into diglyceride (DG) and monoglyceride (MG) and no fatty acid methyl esters (FAMEs, E). Then, the initial response time is ignored completely because detection object is only FAMEs.

There will be a large amount of FAMEs product only when DG and MG are accumulated to a certain amount in the $[\mathrm{BMIM}]\left[\mathrm{PF}_{6}\right]$ reaction system. Although we should modify the reaction model to minimize response time delay,

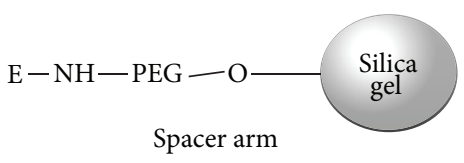

FIGURE 5: Comparison of the determined and the model prediction.

time delay is not well defined because of the large differences among different reaction systems.

\section{Conclusions}

Biodiesel, a renewable, biodegradable, nontoxic, and clean fuel, which is made from plant oil or animal oil, is expected as a part of substitute for conventional fossil diesel. There are some advantages for ionic liquids with low volatility, incombustibility, electrical conductivity, big heat capacity, and small vapor pressure, stabilities, and good solubility for many inorganic and organic compounds. Lipase-catalyzed biodiesel production models in room temperature ionic liquids (RTILs) reaction medium available in the literature are valid especially for mixing intensity.

Ionic liquids are also considered for use in enzyme catalysis because they are safe for the environment as they do not evaporate. These environmental and economic considerations give ionic liquids a green image. The widely used anion hexafluorophosphate, $\mathrm{PF}_{6}{ }^{-}$, decomposes and releases $\mathrm{HF}, \mathrm{a}$ very harmful acid [14]. This is not only a disadvantage in view of sustainability but also a drawback for emerging biphasic processing, where $\mathrm{PF}_{6}{ }^{-}$is chosen for its immiscibility properties with aqueous solutions. It could only be attributed to $[\mathrm{BMIM}]\left[\mathrm{PF}_{6}\right]$ that ionic liquid molecules which adhered on Limczyme molecules because of its viscosity might not be completely cleaned and affect the reuse of Limczyme for the enzymatic production biodiesel. Alternative anions should be therefore under development.

A preliminary model is established in order to try to describe the lipase-catalyzed biodiesel production process in RTILs in a stirring type bioreactor. The model predicts the evolution of the transesterification producing biodiesel for a unique stirring frequency of stirrer. Mixing intensity and time delay being dependent on the stirring frequency of stirrer were inspected for the reaction model in $[\mathrm{BMIM}]\left[\mathrm{PF}_{6}\right]$ medium. As a result, this model is a good explanation for these actual reaction conditions in RTILs. The model prediction curve well describes the experimental data and is effective and reliable in certain conditions. So the model described in this paper could effectively be used in enzymatic reactions, notably in biodiesel production processes in $[\mathrm{BMIM}]\left[\mathrm{PF}_{6}\right]$ reaction system.

\section{Nomenclature}

\section{Abbreviations}

RTILs: Room temperature ionic liquids

TG: Triglyceride

DG: Diglyceride

MG: Monoglyceride. 


\author{
Symbols \\ C: $\quad$ Concentration of chemical species, $\mathrm{mol} \cdot \mathrm{dm}^{-3}$ \\ $t$ : $\quad$ Reaction time, min \\ $T$ : $\quad$ Reaction temperature, $\mathrm{K}$ \\ $f$ : Right-side hand function in the ODE model, \\ mol dm ${ }^{-3} \min ^{-1}$ \\ $H$ : Heaviside function \\ $\theta: \quad$ Time delay factor, min \\ $\eta: \quad$ Effectiveness factor, dimensionless \\ $r: \quad$ Stirring rate, $\mathrm{rpm}$ \\ $k_{1}$ : $\quad$ Parameter in (2), dimensionless \\ $k_{2}$ : $\quad$ Parameter in (2), $\mathrm{rpm}^{-1}$ \\ $k_{3}$ : $\quad$ Parameter in (2), rpm \\ $k_{4}$ : $\quad$ Parameter in (3), rpm \\ $k_{5}$ : $\quad$ Parameter in (3), min \\ $V_{\max }:$ The largest reaction rate, $\mathrm{mol} \cdot \mathrm{m}^{-3} \cdot \mathrm{min}^{-1} \cdot \mathrm{g}^{-1}$ \\ $a K_{m 1}$ : Michaelis constant of Tung oil, mol $\cdot \mathrm{m}^{-3}$ \\ $K_{m 2}:$ Michaelis constant of methanol, $\mathrm{mol} \cdot \mathrm{m}^{-3}$ \\ $K_{\mathrm{iMe}}:$ Methanol inhibition constant, $\mathrm{mol} \cdot \mathrm{m}^{-3}$.
}

\section{Disclosure}

This paper was written by JianJun Yang and MingYan Yang. Both authors have read and approved this version of the paper, and due care has been taken to ensure the integrity of the work.

\section{Conflict of Interests}

The authors declare that there is no conflict of interests regarding the publication of this paper.

\section{Acknowledgments}

This project was supported by China Postdoctoral Science Foundation Funded Project (no. 2012M511963) and the Special Fund for Basic Scientific Research of Central Colleges, Chang'an University (no. CHD2009JC094).

\section{References}

[1] H. Zhao and G. A. Baker, "Ionic liquids and deep eutectic solvents for biodiesel synthesis: a review," Journal of Chemical Technology and Biotechnology, vol. 88, no. 1, pp. 3-12, 2013.

[2] A. H. M. Fauzi and N. A. S. Amin, "Optimization of oleic acid esterification catalyzed by ionic liquid for green biodiesel synthesis," Energy Conversion and Management, vol. 76, pp. 818827, 2013.

[3] N. Pang, S.-S. Gu, J. Wang et al., "A novel chemoenzymatic synthesis of propyl caffeate using lipase-catalyzed transesterification in ionic liquid," Bioresource Technology, vol. 139, pp. 337342, 2013.

[4] L. Andreani and J. D. Rocha, "Use of ionic liquids in biodiesel production: a review," Brazilian Journal of Chemical Engineering, vol. 29, no. 1, pp. 1-13, 2012.

[5] J. J. Yang, X. X. Ma, Z. S. Zhang, B. Chen, S. Li, and G. J. Wang, "Lipase immobilized by modification-coupled and adsorption-cross-linking methods: a comparative study," Biotechnology Advances, vol. 28, no. 5, pp. 644-650, 2010.

[6] K.-P. Zhang, J.-Q. Lai, Z.-L. Huang, and Z. Yang, "Penicillium expansum lipase-catalyzed production of biodiesel in ionic liquids," Bioresource Technology, vol. 102, no. 3, pp. 2767-2772, 2011.

[7] Z. Yang, K.-P. Zhang, Y. Huang, and Z. Wang, "Both hydrolytic and transesterification activities of Penicillium expansum lipase are significantly enhanced in ionic liquid $[\mathrm{BMIm}]\left[\mathrm{PF}_{6}\right]$," Journal of Molecular Catalysis B: Enzymatic, vol. 63, no. 1-2, pp. 2330, 2010.

[8] A. S. R. Brásio, A. Romanenko, L. O. Santos, and N. C. P. Fernandes, "Modeling the effect of mixing in biodiesel production," Bioresource Technology, vol. 102, no. 11, pp. 65086514, 2011.

[9] J. E. F. Carmo and A. G. B. Lima, "Mass transfer inside oblate spheroidal solids: modelling and simulation," Brazilian Journal of Chemical Engineering, vol. 25, no. 1, pp. 19-26, 2008.

[10] J. J. Yang, Study on immobilization of lipase and catalytic synthesis of biodiesel in ionic liquids [Ph.D. thesis], Northwestern University, Xi'an, China, 2009.

[11] M. Adamczak, U. T. Bornscheuer, and W. Bednarski, "Synthesis of ascorbyloleate by immobilized Candida antarctica lipases," Process Biochemistry, vol. 40, no. 10, pp. 3177-3180, 2005.

[12] J. P. Hallett and T. Welton, "Room-temperature ionic liquids: solvents for synthesis and catalysis. 2," Chemical Reviews, vol. 111, no. 5, pp. 3508-3576, 2011.

[13] J. J. Yang, "Study on the reaction mechanism of lipase-catalyzed synthesis FAMEs in room temperature ionic liquids reaction systems," Postdoctoral Research Report, Chang'an University, Xi'an, China, 2014.

[14] F. Fischer, J. Mutschler, and D. Zufferey, "Enzyme catalysis with small ionic liquid quantities," Journal of Industrial Microbiology \& Biotechnology, vol. 38, no. 4, pp. 477-487, 2011. 

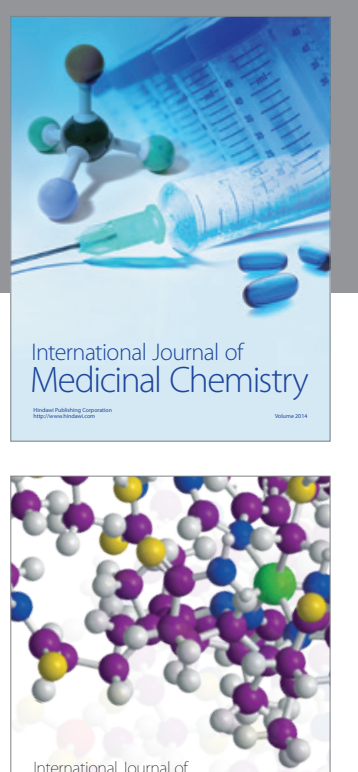

Carbohydrate Chemistry

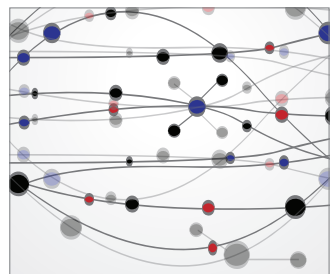

The Scientific World Journal
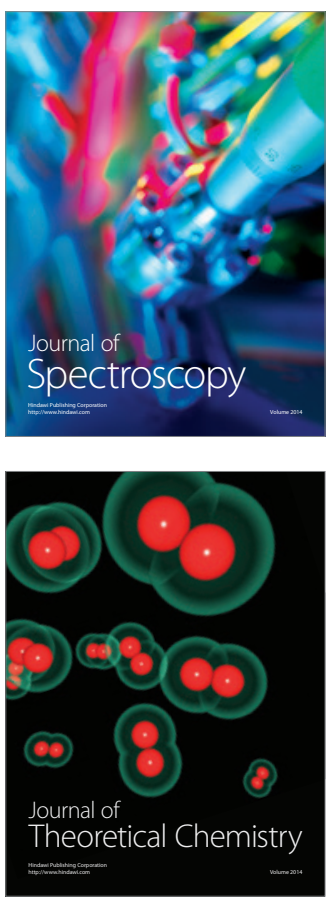
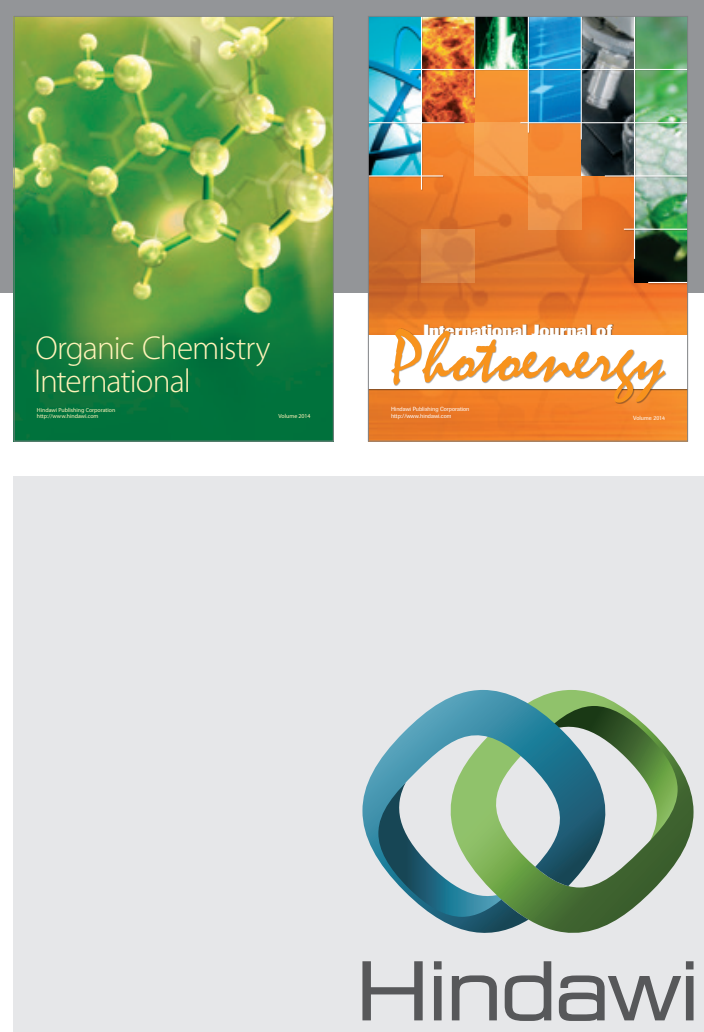

Submit your manuscripts at

http://www.hindawi.com

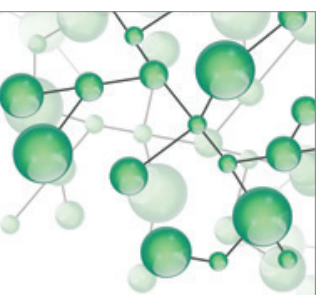

International Journal of

Inorganic Chemistry

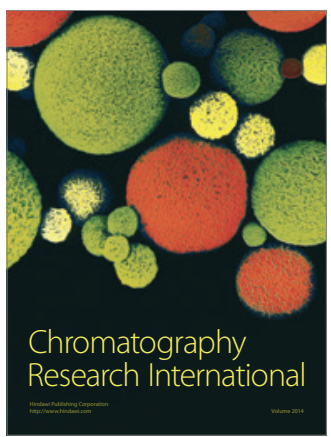

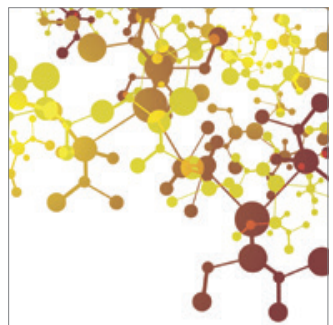

Applied Chemistry
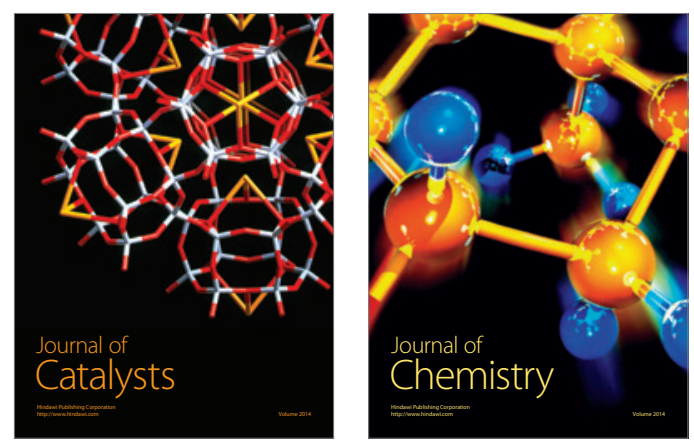
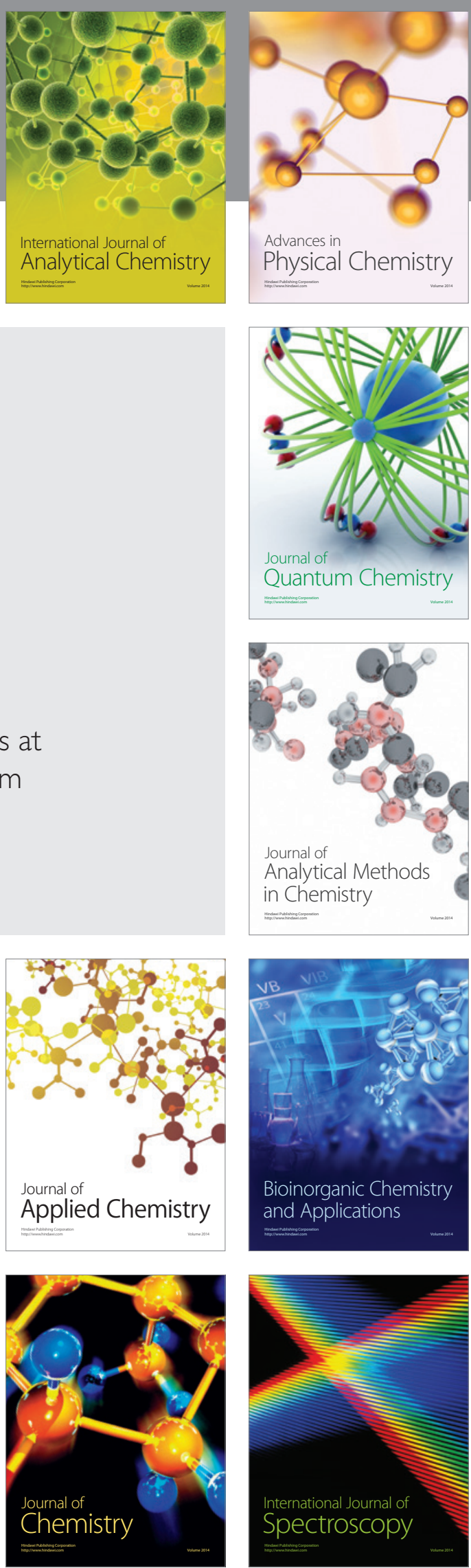